\title{
Editorial
}

www.anatomy.org.tr

doi:10.2399/ana.10.005x

\section{University Professor Josef Stingl, MD, PhD, JUBILEE}

Anatomy 2010; 4 Suppl 1: 5 @ 2010 TSACA

\section{Dear Professor Stingl,}

These days, here in the middle of the Congress you have organised, you will celebrate your $70^{\text {th }}$ birthday. Having the privilege to be your friend, I take the honour to comment on this event and present your portrait to this scientific community.

You started your medical education at the Medical Faculty of the Charles University in Plzeň where you were soon recognised as one of the most talented students. All our young community admired your acute sense of duty, respect for a serious work, and warm idealism crystallising in a humble and deeply empathic attitude towards the human suffering. Your fun-loving and unselfish character made of you our beloved companion.

Immediately fascinated by morphological disciplines, you started your anatomical career right from the second semester of the first year, so that, when you brilliantly had obtained your medical degree, you were already a well formed, skilled and highly appreciated teacher. Over years, your rich pedagogical experience led to publication of several largely used anatomical guides and textbooks.

Furthermore and most remarkably, you took also a formation in surgery and have never lost contact with the patient. All along your academic career, you thus followed a difficult but passionate "double existence", spending innumerable nights and weekends on duty in your regional hospital and confronting anatomical knowledge with the problems of reality. Who if not you can better defend the motto "Anatomia clavis et clavus medicinae" crowning the entry of your institute at the Third Medical Faculty in Prague?

As researcher, you have been mainly interested in problems concerning the ontogenesis of skeleto-motor system and your systematic studies of the vascular system of skeletal muscles have been condensed in several monographies. Your elegant ultramicroscopic studies of the muscular angiogenesis and microcirculation show how a morphological description can be efficiently combined with a dynamic and experimental approach and suggest attractive functional hypotheses. You were also much involved in multidisciplinary projects aimed on evaluation and prevention of traffic accidents. Your scientific contribution was recognised by attribution of many grants and awarded several times by the Ministry of Health of the Czechoslovak Republic and Czechoslovak Anatomical Society.

You officiated as Vice-President of the European Association for Clinical Anatomy and have been without interruption actively involved in the political and social life of the academic community of Prague: at the Third Medical Faculty as the Vice-Dean for research and science and member of the Scientific Council; at the University level as a member of the Presidium of the Grant Agency and, finis coronat opus, as the Vice-Rector of the Charles University.

So, dear Professor Stingl, dear Friend, you are now approaching the seventies and you do it admirably! For all of us, you are the example of enthusiastic teacher, passionate scientist, selfless physician, man respecting the promises and truth. I can not think of a better conclusion than that written by a student of yours in an official evaluation document: “...when I will grow up I want to be like Josef Stingl...”!

With all your collaborators I thank you for your efforts, congratulate you for your achievements and wish you all the best for the forthcoming years. May they be many!

Yours truly,

Pavel Kucera Professor of Physiology, University of Lausanne, Switzerland 